\title{
The Glutamatergic Synaptic Transmission Mediated by Ionotropic Glutamate Receptors in Rats Cerebral Cortex in Behavioral Depression
}

\author{
Igor I. Abramets, Yulia V. Sidorova, Dmitriy V. Evdokimov and \\ Alexander N. Talalayenko
}

Department of Pharmacology M. Gorky National Medical University, Donetsk, Ukraine

Correspondence should be addressed to: Igor I. Abramets; abrametz2009@yandex.ru

Received 12 June 2013; Accepted 15 July 2013; Published 30 November 2013

Academic Editor: Sergey O.Bachurin

Copyright @ 2013 Igor I. Abramets, Yulia V. Sidorova, Dmitriy V. Evdokimov and Alexander N. Talalayenko. Distributed under Creative Commons CC-BY 3.0

\begin{abstract}
In experiments on rats was simulated the behavioral depression caused by social isolation and chronic inflammation. It was found in slices of the medial prefrontal cortex that behavioral depression was attained by the inhibition of the basal glutamatergic synaptic transmission in the layer $\mathrm{V}$ pyramidal neurons of the medial prefrontal cortex, that was manifested by decay of the amplitude of field (f) excitatory postsynaptic potentials (EPSPs). The increase of amlitude of $\mathrm{N}$-methyl-D-aspartate (NMDA) component of fEPSPs in addition observed. Last effect was conditioned by the increase of the functional activity of the NMDA receptors (NMDARs) containing NR2A subunit. The increase of functional activity of the NMDARs evoked inhibition of the basal glutamatergic synaptic transmission in the pyramidal neurons, whereas it was prevented by systemic administration of NMDARs blocker ketamine. It was observed also under behavioral depression disturbances of the plastic properties of cortical synapses, which become apparent by the inhibition of the expression of long-term potentiation and long-term depression of synaptic transmission, but with the reinforcement of the last under the induced by social isolation of behavioral depression. The disturbances of synaptic plasticity are conditioned par excellence by increase of functional activity of verapamil-sensetive $\mathrm{Ca}^{2+}$ channels.
\end{abstract}

Keywords: Behavioral Depression; Glutamatergic Synaptic Transmission; NMDA Receptors; AMPA Receptors.

\section{Introduction}

According to NMR- and PET-spectroscopy patients with depressive disorders has higher local blood flow and elevation of glucose metabolism in certain limbic structures of a brain compared to nondepressed people (Mayberg et al., 1999 and Moore et al., 2009). Depressive state is generally associated with activation of the neuronal ensembles in dorsolateral prefrontal cortex, subgenual part of anterior cingulate cortex, amygdala, and ventrolateral thalamus (Price and Drevets, 2010). The projection neurons of these structures are glutamatergic. Thus it is reasonable to suppose that one of the neurophysiological components of

Cite this Article as: Igor I. Abramets, Yulia V. Sidorova, Dmitriy V. Evdokimov and Alexander N. Talalayenko (2013), "The Glutamatergic Synaptic Transmission Mediated by Ionotropic Glutamate Receptors in Rats Cerebral Cortex in Behavioral Depression," Research in Neurology: An International Journal, Vol. 2013 (2013), Article ID 159123, DOI: 10.5171/2013.159123 
depressive syndrome is the reinforcement of the excitatory glutamatergic neurotransmission in some brain limbic structures. But experimental studies in animal modelling of depressive syndrome show that glutamatergic synaptic transmission that realizes with the involvement of $\alpha$-amino-3-hydroxy-5methyl-4-isoxazolepropionic acid (AMPA) receptors remains unchanged or even becomes suppressed (Abramets et al., 2005 and Pickering et al., 2006). This data indicates that the functional activity of the AMPA receptors (AMPARs) in postsynaptic densities of dendritic spines is usually decreased under depressive state. This hypothesis is supported by the fact that using of the drugs, which elevate chemosensitivity of AMPARs, increases therapeutic activity of the antidepressants (Li et al., 2001). Furthermore, it is shown that electroconvulsive therapy, which is one of the most effective methods of depressive disorders treatment, causes the increase of the AMPARs number in postsynaptic densities of dendrite spines (Burnham et al., 1995).

Basal glutamatergic synaptic neurotransmission in mammalian brain is performed as a result of the interaction between glutamate and postsynaptic ionotropic AMPARs and NMDARs, which evokes generation of the excitatory postsynaptic currents (EPSCs). A generation of fast EPSCs is outcome of activation of the synaptic AMPARs. The quantity of these receptors in the postsynaptic densities of dendrite spines is changeable and is regulating by a number of factors such as neuronal activity, plasticity, the activity of NMDARs and others (Derkach et al., 2003 and Ehlers et al., 2007).

At the same time, the information about the functional status of the neuronal NMDARs within the brain limbic structures in animals and patients with depressive syndrome is ambiguous. On one hand, it is known that production of D-serine, which works as a co-agonist of NMDARs, is decreasing and the effects of the NMDARs blockers are enhancing under depression state (Cappiello et al., 1997 and Krystal et al., 2002); and it can be regarded as the evidence of hypofunction of NMDARs. On the other hand, there is evidence, that the NMDARs blockers attenuate the symptoms of depressive syndrome (Berman et al., 2000), which indicate the increase of the functional activity of NMDARs in the given situation. In its turn, the NMDARs functional activity is regulating by the number of factors, among which are level of phosphorilation of the receptor subunits, plasticity, the impact of monoaminergic neurons on the cortical neurons and others (Kohr, 2006 and Lau and Zukin, 2007).

Here we investigated the effect of behavioral depression caused by social isolation and chronic inflammation in rats on the status of glutamatergic synaptic transmission and postsynaptic glutamate receptors in pyramidal neurons of the medial prefrontal cortex (mPFC).

\section{Material and Methods}

\section{Animals}

The studies were carried out on white inbred rats of both sexes, 8 - 10 weeks old, weighting $200-250 \mathrm{~g}$, which were kept in cages for $4-6$ individuals, under 12 hours cycle of light/dark time. The light was switched on at 7.00. The rats had free access to food and water. The studies were performed in accordance with requirements of the Bioethics Commission of the M. Gorky Donetsk National Medical University. Animals were randomly allocated into the three equivalent groups $(n=12$ in each). Behavioral depression in rats from $1^{\text {st }}$ and $2^{\text {nd }}$ groups was induced by the chronic aseptic inflammation and social isolation, respectively; in $3^{\text {rd }}$ group rats were maintained in common conditional and were used as a control.

\section{Simulation of Behavioral Depression}

Chronic aseptic inflammation in rats was done as described before (Trinus et al., 1975). Briefly: acetic acid solution (9\%, $0.5 \mathrm{ml}$ ) was injected subcutaneously (under the skin of the dorsum); immediately after the rats were injected intraperitonialy with dextran solution $(200 \mathrm{mg} / \mathrm{kg})$. Within 2 -3 
days an inflammatory infiltrate at the site of acetic acid injection was developed. The intensity of inflammatory process was estimated by the increased number of leucocytes in blood and the size of the inflammatory infiltrate. Social isolation was performed during 5 days by transferring rats from family cage into the experimental one (size: $15 \times 30 \mathrm{~cm}$, height $10 \mathrm{~cm}$ ), which limited the horizontal and vertical movements of rats, but still has free access to meal and water. 24 hours after the termination of social isolation (1 $1^{\text {st }}$ group) and on the $7^{\text {th }}$ day after the acetic acid injection (2 $2^{\text {nd }}$ group) rats underwent series of the behavioral tests to assess development of depressive state. Development of the depressive state was determined by the next criteria: increase of the immobilization time in forced swimming test (Porsolt et al., 1978) - 200 $220 \mathrm{~s}$ vs $125 \mathrm{~s}$ in control rats, reduction of time spend in the open arm entries of the X-maze (Handley, Mithani, 1984) - 80 - 90 $\mathrm{s}$ vs $136 \mathrm{~s}$ in control rats and impairment of the active avoidance formation and realization skill (Knoll et al., 1955) increase of latent time of the conditioned reaction to $3-4 \mathrm{~s}$ vs $1,75 \mathrm{~s}$ in control rats. Only rats that developed behavioral depression were used for further experiment. None of the control rats showed depressive signs by the mentioned above tests.

\section{Electrophysiological Protocols}

Experimental

Electrophysiological studies were performed on the brain slices of mPFC as described earlier (Abramets et al., 2007). Briefly, the rats were terminally anesthetized by intraperitoneal administration of ketamine $(50 \mathrm{mg} / \mathrm{kg})$ and decapitated. Brain was removed from the skull and immediately cooled with a dissection solution till $4-6^{\circ} \mathrm{C}$. Prefrontal cortex was isolated from the front pole of the brain, which was fixed on the plate of a vibratom. Coronal bilateral brain slices ( $400 \mu \mathrm{m}$ thick) that included the prelimbic and infralimbic prefrontal cortex were cut in a bath of vibratom filled with cooled carbogen-saturated dissection solution. The composition of this solution was the following (mM): sucrose, 248; $\mathrm{NaHCO}_{3}, 26$; $\mathrm{KCl}, 3 ; \mathrm{KH}_{2} \mathrm{PO}_{4}, 1,25 ; \mathrm{CaCl}_{2} 0,1 ; \mathrm{MgSO}_{4}, 3$, and glucose, 10 . Then section of MPFC were isolated from slices of the anterior cerebral pole and were placed into the incubation chamber, where they were superfused in Krebs solution of the following composition in $\mathrm{mM}: \mathrm{NaCl}, 124 ; \mathrm{NaHCO}_{3}, 26 ; \mathrm{KCl}, 3$; $\mathrm{KH}_{2} \mathrm{PO}_{4}, 1,25 ; \mathrm{CaCl}_{2}, 2 ; \mathrm{MgSO}_{4}, 1$, and glucose, 10 . The solution in the incubation chamber (volume $2 \mathrm{ml}$ ) was continuously aerated with carbogen; the flow rate through chamber, temperature, and $\mathrm{pH}$ of the solution (saturated with carbogen) were $2 \mathrm{ml} / \mathrm{min}, 25{ }^{\circ} \mathrm{C}$, and 7,3 respectively. In $90 \mathrm{~min}$ of the incubation one of the slices was placed from incubation chamber into a $0,5 \mathrm{ml}$ working chamber, where it was perfused with carbogen saturated Krebs solution at a temperature $28 \pm 0,5^{\circ} \mathrm{C}$; flow rate was 2 $\mathrm{ml} / \mathrm{min}$.

Field EPSPs of pyramidal neurons from $\mathrm{V}$ stratum of the mPFC were extracellularly recorded by glass microelectrodes filled by 2,0 $\mathrm{M} \mathrm{NaCl}$ (tip resistance 1 to $3 \mathrm{M} \Omega$ ) using the AC UBP-04 amplifier (input gain to 5000; bandwidth to $80 \mathrm{kHz}$ ); they were digitized, using 10-order $\mathrm{AD}$ converter, and were recorded in analog and digital forms on the hard disc of a PC. The examined fEPSPs were evoked by electrical stimulation via bipolar nichrome electrode (inter-tip distance $50 \mu \mathrm{m}$ ) positioned in the II stratum of $\mathrm{mPFC}$, where afferents of the medidorsal thalamus pass over. A distance between stimulating and recording electrodes was $1-1,5 \mathrm{~mm}$. Similar localization of the stimulating and recording electrodes was used in the investigation of Zushida et al (2007) and Fortin and Levine (2007). The stimulation was performed with a constant current mode $100 \mu$ s duration and frequency 0,033 Hz. A dependence of the fEPSPs amplitude on the intensity of a presynaptic stimulation was investigated after stabilization of the fEPSPs.

The NMDA component of the fEPSPs of cortical pyramidal neurons was isolated pharmacologically. For this, the cortex slices were superfused with Krebs solution with the reduced concentration of $\mathrm{Mg}^{2+}$ till 
$0,2 \mathrm{mM}$ and with addition of $10 \mu \mathrm{M}$ of the AMPARs blocker DNQX, $50 \mu \mathrm{M}$ of blocker of the $\mathrm{GABA}_{\mathrm{A}}$ receptor picrotoxine, and $1 \mu \mathrm{M}$ of the NMDARs co-agonist glycine (RBI, USA). The postsynaptic potentials which registrated under this condition at distinction from long-lasting epileptiform discharges entirely were blocked by $50 \mu \mathrm{M}$ of D-2-amino-5-phosphonovaleric acid (competitive blocker of NMDARs) and did not altered by high concentration $(25 \mu \mathrm{M})$ of DNQX.

Besides, the two forms of synaptic plasticity of cortical pyramidal neurons long-term potentiation (LTP) and longterm depression (LTD) were examined. LTP was evoked by tetanic stimulation $(100 \mathrm{~Hz}, 1 \mathrm{~s})$ of the II stratum of mPFC; the intensity of presynaptic stimulation was adjusted so that fEPSPs amplitude makes up $1 / 3$ on maximal. LTD was evoked by low frequency ( $3 \mathrm{~Hz}, 5 \mathrm{~min}$ ) tetanic stimulation of the synaptic inputs; the intensity of presynaptic stimulation was adjusted to be submaximal (0,7-0,8 of maximal). Each set of the electrophysiological experiments was carried out on 6-9 brain slices taken from 3-4 animals.

\section{Statistical Analysis}

All data are presented as means \pm SEM. Results were analyzed using analysis of variance (ANOVA) followed StudentNewman-Keuls test for evaluation differences between more than two groups. Comparisons between two groups involved usage of the Student's t test. $\mathrm{P}<0,05$ was considered statistically significant.

\section{Results}

Changing of the Glutamatergic Synaptic Transmission due Behavioral Depression Caused by Social Isolation and Chronic Inflammation

We have found specific changes in glutamatergic synaptic transmission in
mPFC taken from rats that developed behavioral depression in response to social isolation. The curves of dependence of the fEPSP amplitudes from intensity of presynaptic stimulation characterized by value of a slope of curve, which was determined from linear regression in the linear range (generally $5 \mathrm{~V}$ stimulation) of the input-output relationship estabilished by plotting the amplitude of fEPSPs in response to voltage pulse $(\mathrm{mV} / \mathrm{V})$. It was significantly decreased in rats with behavioral depression (Fig. 1) compared to controls $(0.60 \pm 0.04 \mathrm{mV} / \mathrm{V}$ vs $0.85 \pm 0.06$ $\mathrm{mV} / \mathrm{V}$, respectively, $\mathrm{P}=0.02)$. Depressive state was also associated with reduction of the maximal amplitudes of the fEPSPs by 20-25\% (Fig. 1C), but not with the alteration of a pulse paired ratio size of fEPSPs (do not illustrated), indicating on the postsynaptic nature of the observed changing. At the same time, the increase in the amplitude of NMDA component of fEPSPs from pyramidal neurons by $20-30$ $\%$ was also observed (Fig. 1B, C). A slope of curve dependence of amplitude of NMDA components of the fEPSPs from intensity of presynaptic stimulation at rats with depression was $0.53 \pm 0,03 \mathrm{mV} / \mathrm{V}$ compared to $0.32 \pm 0,03 \mathrm{mV} / \mathrm{V}$ in control rats $(P=0,04$, Fig. $1 C)$. Same changes were observed in fEPSPs from rats, in which behavioral depression was induced by chronic aseptic inflammation (Fig. 2). 


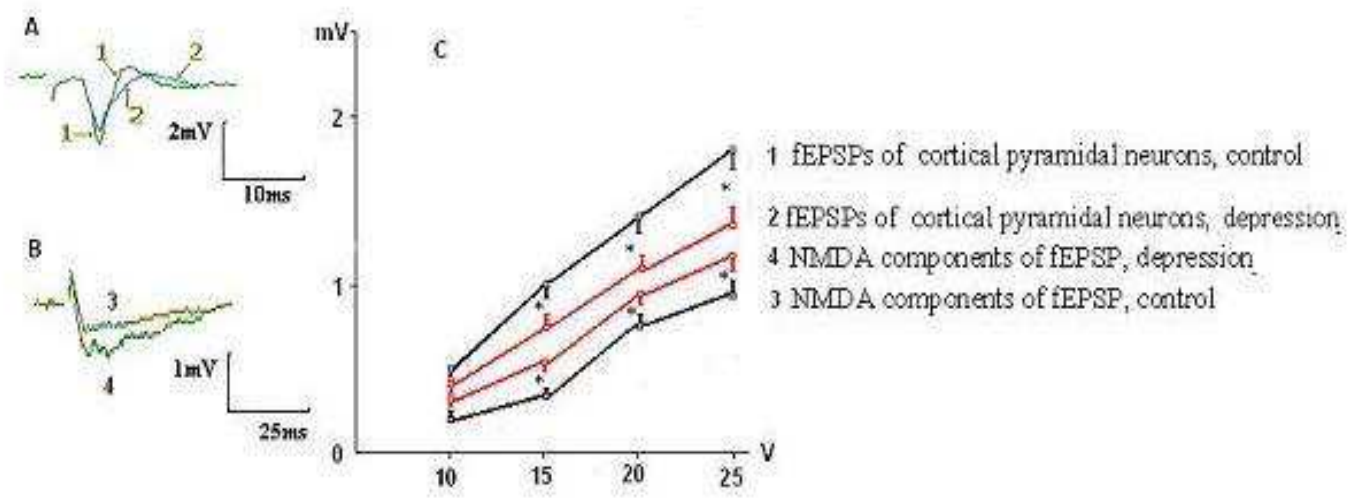

Fig. 1. Decay of fEPSP Amplitudes and Increasing of the NMDA Components of fEPSPs of the Layer V Pyramidal Neurons of mPFC in Rats with Behavioral Depression was Evoked by Social Isolation. A. Representative Record of Maximal fEPSPs of Cortical Pyramidal

Neurons; B. Representative Record of Maximal NMDA Components of fEPSP; C.

Dependence of fEPSP Amplitude and NMDA Components of fEPSP (mV) from the Presynaptic Stimulation Intensity (V). The Resistance of Stimulating Electrode is $200 \mathrm{k} \Omega$. * - P $<0,05$

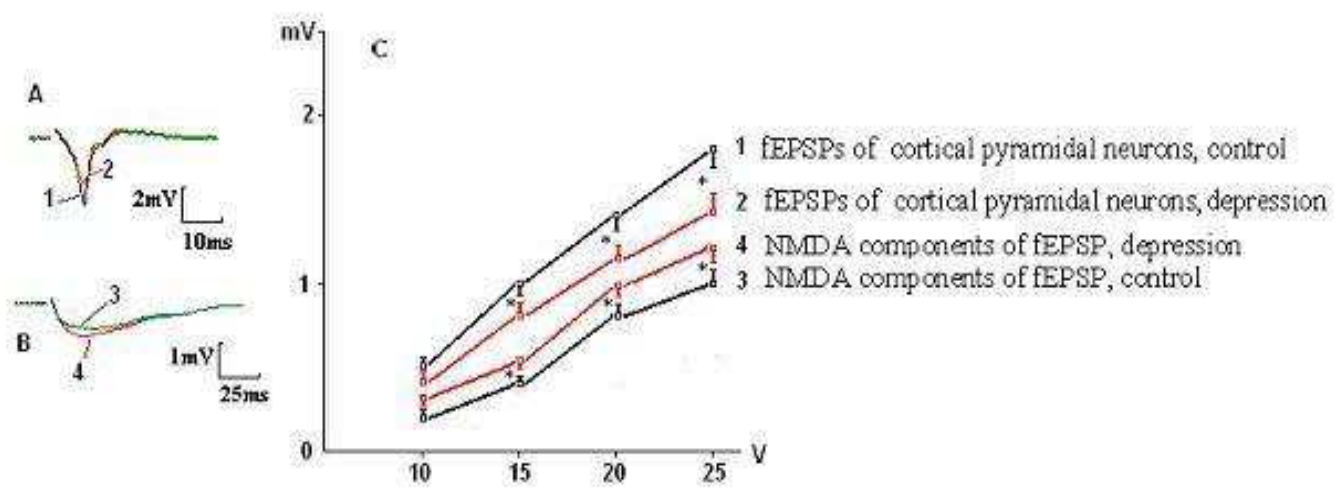

Fig. 2. Decay of fEPSP Amplitudes and Increasing of the NMDA Components of fEPSPs of the Layer V Pyramidal Neurons of mPFC in Rats with Behavioral Depression was Evoked by Chronic Inflammation. The Denotations as in Fig. 1

We also found that NMDA components of the fEPSPs, which was significantly higher in slices from the depressed rats (Tab. 1), was dramatically reduced by application of D-2-Amino-5-Phosphonovaleric acid (50 $\mu \mathrm{M}$; D-APV, RBI, USA), which specifically competitively blocks NMDARs, whereas fEPSPs were not significantly changed by D-APV. Whereas ketamine has NMDA blocking and antidepressive activity (Berman et al., 2000) we desided to examine it influence on behavioral and electrophysiological occurences of depressive syndrome.

6 injection of ketamine (Biolek, Ukraine), which is non competitive NMDARs blocker, during social isolation $(30 \mathrm{mg} / \mathrm{kg} 2$ times daily on $3^{\text {rd }}-5^{\text {th }}$ days of the isolation) led to the attenuation of the manifestations of behavioral depression. For example, after course of administration of ketamine the time of immobilization in swimming test and one spend in the open arm entries of 
the X-maze decrease and inrease to $170,1 \pm$ $5,2 \mathrm{~s}$ and $102,6 \pm 6,7 \mathrm{~s}$ respectively vs 211,3 $\pm 7,7 \mathrm{~s}$ and $82,6 \pm 6,2$ after social isolation only. This procedure return of amplitudes of fEPSPs and its NMDA component on the level of control rats (Tab. 1) Addition to the perfusion solution of L-type calcium channel blocker Verapamil (20 $\mu \mathrm{M}$; Orion Pharma Int, Finland) did not restore neither monitoring changes in glutamate neurotransmission, that were caused by behavioral depression due to social isolation.

\section{Table 1. Changes of Amplitudes of fEPSPs of Pyramidal Neurons and its NMDA} Components at Rats under Social Isolation

\begin{tabular}{|c|c|c|c|c|c|}
\hline & \multirow[t]{2}{*}{ Control rats } & \multicolumn{2}{|r|}{ Depressive } & \multicolumn{2}{|l|}{ syndrome } \\
\hline & & $\begin{array}{l}\text { No } \\
\text { interventions }\end{array}$ & $\begin{array}{l}50 \mu \mathrm{M} \text { D-APV } \\
\text { added to slice }\end{array}$ & $\begin{array}{l}\text { Ketamine } 30 \\
\mathrm{mg} / \mathrm{kg} \text {, } \\
\text { during social } \\
\text { isolation }\end{array}$ & $\begin{array}{l}20 \mu \mathrm{M} \text { of } \\
\text { Verapamile } \\
\text { added to } \\
\text { slice }\end{array}$ \\
\hline fEPSPs, mV & $\begin{array}{l}1,04 \pm 0,05 \\
(12)\end{array}$ & $\begin{array}{l}0,78 \pm 0,04 * \\
(10)\end{array}$ & $\begin{array}{l}0,70 \pm 0,04 \\
(10)\end{array}$ & $\begin{array}{l}0,98 \pm 0,04 \# \\
(10)\end{array}$ & $\begin{array}{l}0,84 \pm 0,06 \\
(10)\end{array}$ \\
\hline $\begin{array}{l}\text { NMDA } \\
\text { component } \\
\text { of fEPSPs, } \\
\mathrm{mV}\end{array}$ & $\begin{array}{l}0,35 \pm 0,03 \\
(12)\end{array}$ & $\begin{array}{l}0,52 \pm 0,04^{*} \\
(10)\end{array}$ & $\begin{array}{l}0,03 \pm 0,04 \# \\
(10)\end{array}$ & $\begin{array}{ll}0,42 \pm & 0,04 \\
(10) & \end{array}$ & $\begin{array}{l}0,55 \pm 0,04 \\
(10)\end{array}$ \\
\hline
\end{tabular}

* - mean statistically different from the control; \# - represents statistical differences of pharmacological intervention compared "no intervention" column.

The analogous results were received under environmets of chronic inflammation, when rats received ketamine on $4^{\text {th }}-7^{\text {th }}$ days after administration of flogogens (Tab. 2).

\section{Table 2. Changes of Amplitudes of fEPSPs of Pyramidal Neurons and its NMDA Components at Rats under Chronic Inflammation}

\begin{tabular}{|c|c|c|c|c|c|}
\hline & \multirow[t]{2}{*}{ Control rats } & \multicolumn{2}{|r|}{ Depressive } & \multicolumn{2}{|l|}{ syndrome } \\
\hline & & $\begin{array}{l}\text { No } \\
\text { interventions }\end{array}$ & $\begin{array}{l}50 \mu \mathrm{M} \text { D-APV } \\
\text { added to slice }\end{array}$ & $\begin{array}{l}\text { Ketamine } 30 \\
\text { mg/Kg, during } \\
\text { inflammation }\end{array}$ & $\begin{array}{l}20 \mu \mathrm{M} \text { of } \\
\text { Verapamile } \\
\text { added to } \\
\text { slice }\end{array}$ \\
\hline fEPSPs, $\mathrm{mV}$ & $\begin{array}{l}1,11 \pm 0,04 \\
(12)\end{array}$ & $\begin{array}{l}0,80 \pm 0,03^{*} \\
(10)\end{array}$ & $\begin{array}{l}0,76 \pm 0,04 \\
(10)\end{array}$ & $\begin{array}{l}0,93 \pm 0,03 \# \\
(10)\end{array}$ & $\begin{array}{l}0,81 \pm 0,04 \\
(10)\end{array}$ \\
\hline $\begin{array}{l}\text { NMDA } \\
\text { component } \\
\text { of fEPSPs, } \\
\mathrm{mV}\end{array}$ & $\begin{array}{l}0,37 \pm 0,03 \\
(12)\end{array}$ & $\begin{array}{l}0,50 \pm 0,04^{*} \\
(10)\end{array}$ & $\begin{array}{l}0,06 \pm 0,04 \# \\
(10)\end{array}$ & $\begin{array}{l}0,40 \pm \\
(10)\end{array}$ & $\begin{array}{l}0,48 \pm 0,05 \\
(10)\end{array}$ \\
\hline
\end{tabular}

* - mean statistically different from the control; \# - represents statistical differences of pharmacological intervention compared "no intervention" column.

\section{Influence of Behavioral Depression on Chemosensitiveness of the NMDARs}

The NMDA components of the fEPSPs underwent both quantitative (changes in amplitude) and qualitative (changes in pharmacological sensitiveness) alterations due to depressive syndrome caused by social isolation or chronic inflammation. In rats that had behavioral depression due to social isolation or chronic inflammation ketamine, which blocks NMDARs with different subunit composition, inhibited the NMDA components of the fEPSPs significantly weaker than in control one (Tab. 3). A similar effect was observed when we used Zn2+, which is known by its ability to selectively block the NMDARs of 
the NR1/NR2A subunit composition (Izumi et al., 2006). On the other hand, haloperidol, which was available accordingly ours capabilities and in low concentrations selectively blocks NMDARs with NR1/NR2B composition (Ilyin et al., 1996), equally inhibited the fEPSPs NMDA components in rats with behavioral depression and control ones (Tab. 3).

Table 3. Alterations of a Pharmacological Sensitivity of NMDA Components of fEPSPs of the mPFC Pyramidal Neurons in Conditions of Chronic Inflammation and Social Isolation

\begin{tabular}{|l|l|l|l|}
\hline \multirow{2}{*}{$\begin{array}{l}\text { The experi- } \\
\text { mental condions }\end{array}$} & \multicolumn{3}{|c|}{ The degree of suppression of the NMDA component of fEPSPs } \\
\cline { 2 - 4 } & $\begin{array}{l}\text { Ketamine } \\
(30 \mu \mathrm{M})\end{array}$ & $\begin{array}{l}\text { Zinc sulfate } \\
(10 \mu \mathrm{M})\end{array}$ & $\begin{array}{l}\text { Haloperidol } \\
(5 \mu \mathrm{M})\end{array}$ \\
\hline Control & $51,3 \pm 5,5 \%$ & $35,4 \pm 3,7 \%$ & $31,3 \pm 3,8 \%$ \\
\hline $\begin{array}{l}\text { Chronic } \\
\text { inflammation }\end{array}$ & $36,7 \pm 4,3 \% *$ & $27,8 \pm 4,2 \%$ \\
\hline Social isolation & $33,2 \pm 5,1 \% *$ & $30,2 \pm 4,1 \% *$ \\
\hline
\end{tabular}

$*$ - Values significantly different from the control $(\mathrm{P}<0,05)$.

\section{Influence of Behavioral Depression on Synaptic Plasticity}

Experimental behavioral depression caused by social isolation as well as chronic inflammation induced abnormalities in the NMDA-dependent forms of synaptic plasticity in $\mathrm{mPFC}$. Both social isolation and chronic inflammation results in significant reduction of LTP expression after tetanic stimulation of the synaptic inputs (Fig. 3). Development of LTD was weakened in group, where behavioral depression was induced by chronic inflammation, but was significantly facilitated in group with depression caused by social isolation (Fig. 3). When verapamil was applied on the mPFC slices from rats with behavioral depression it restores observed changes of both LTP and LTD expression if behavioral depression was induced by social isolation and chronic inflammation (Fig. 3). This data indicates that behavioral depression causes alterations not only in relay (Fig. 1 and 2) but also in plastic properties of glutamatergic synapses of the $\mathrm{mPFC}$ pyramidal neurons. 

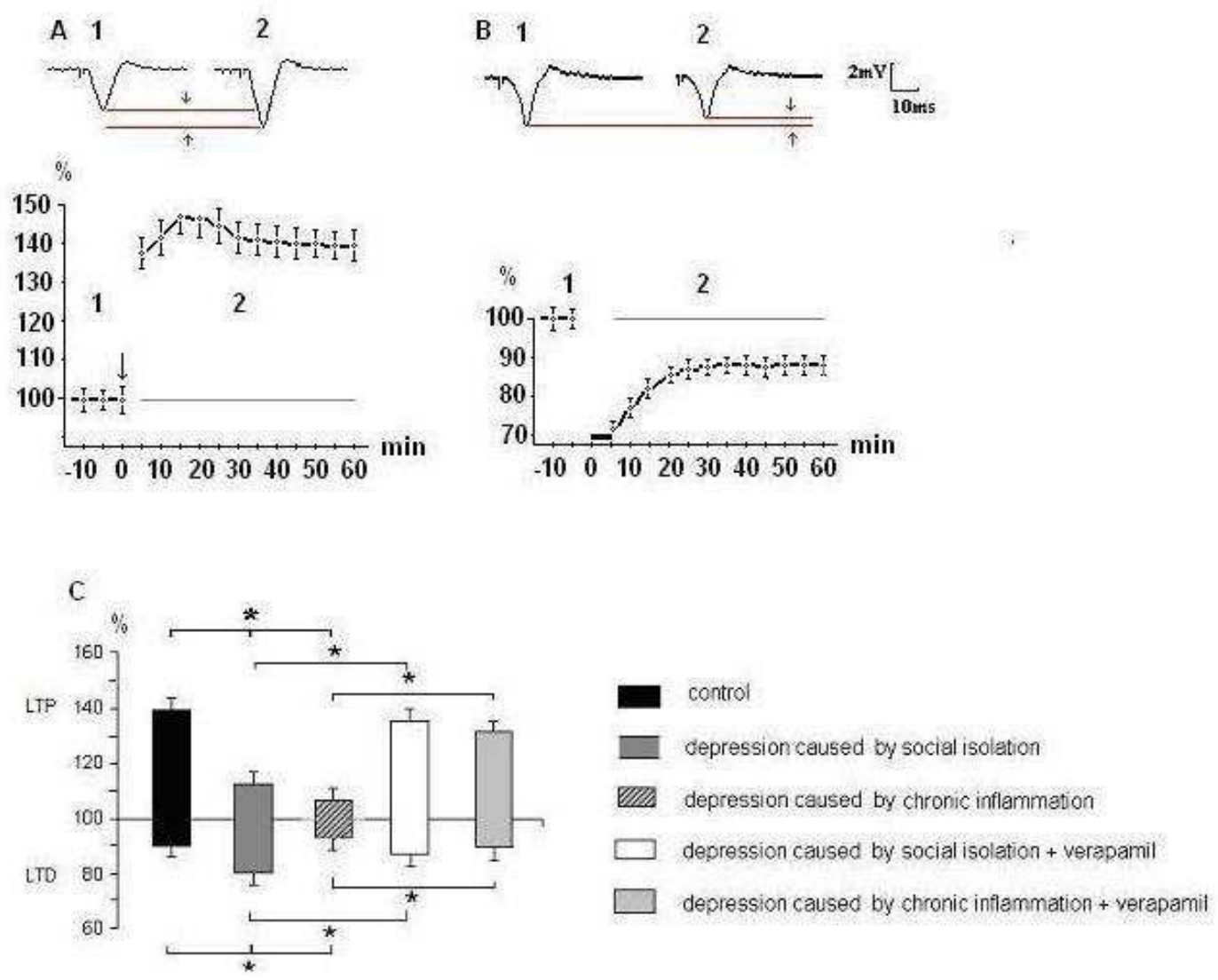

Fig. 3. Alterations of Expression of LTP and LTD of Glutamatergic Synaptic Transmission in $\mathrm{mPFC}$ at Rats with Behavioral Depression

A and B - a dynamics of expression LTP and LTD respectively in control rats; from above representative fEPSP waveforms (average on 10 realizations) taken from experiment sat the times indicated by the numbers on the graph are shown. Vertical scale - the alterations of fEPSPs amplitudes (\%); horizontal one - time from onset high (A, arrow) and low frequency (B, black line) stimulation.

C - the alterations of amplitudes of fEPSPs which were registrated on 30-th min after cessation of tetanic stimulation of the synaptic inputs under different experimental conditions. The upward deviations correspond to LTP, downward LTD of synaptic transmission.

* - Values significantly different from the control $(\mathrm{P}<0,05)$.

\section{Discussion}

In this study we revealed three basic electrophysiological markers of behavioral depression in mPFC. First, decrease of amplitude of fEPSPs of the pyramidal neurons (Fig. and Tab. 1 and 2), i. e. reduction of the glutamatergic synaptic transmission in $\mathrm{mPFC}$. Second, increase of amplitude of NMDA components of pEPSPs and alteration of its sensetivity to action of the NMDA blockers (Fig. 1 and 2, Tab. 3). Third, it was revealed inhibition of LTP and LTD expression, i. e. damage of synaptic plasticity of the pyramidal neurons of mPFC (Fig. 3).

Generation of the glutamatergic EPSPs (EPSCs) in cortical and hippocampal neurons was mediated by activation of the ionotropic AMPA and NMDA glutamate 
receptors (Hestrin et al., 1990). It is possible that attenuation of the basal synaptic transmission is due to the decrease of activity of the AMPARs and NMDARs. However, the increase of NMDA component of the fEPSPs which was observed under behavioral depression (Fig. 1 and 2), contradicts this. It allowed to assume, that the increase of the NMDARs activity evokes attenuation of the fast glutamatergic synaptic transmission. Indeed, system administration of noncompetitive blocker of NMDARs ketamine trough several days of development of behavioral depression evoked attenuation of manifestation of behavioral depression and decrease of amplitude of fEPSPs (Tab. 1 and 2). It agrees with the results of another researchers which estabilished, that prolonged activation of the postsynaptic NMDARs decreased, while theirs blockade increased the AMPA receptors number and amplitude of EPSPs (Kato et al., 2007 and Shi et al., 2001). The increase of currents mediated by NMDARs and attenuation of the basal glutamatergic synaptic transmission in the hippocampus of mice after administration of proinflammatory interleukines observed by Yang et al. (2005) as well.

However, a cause of the increase of NMDARs functional activity remains elusive. Let us consider three probable scenarios. First, the increase of amplitude of NMDA components of fEPSPs may be conditioned by slowing down of glutamate clearence from synaptic and extrasynaptic compartments, whereas how estabilished Malandro and Kilberg (1996) and Muller and Schwarz (2007) hormones of stress and proinflammatory interleukines inhibit activity of the glutamate transporters. It should be supervised in this case the increase of duration of NMDA component of fEPSPs at greater extent as compared with theirs amplitude alterations; moreover, attenuation of NMDA component of fEPSPs by the NMDA blockers with different selectivity must occur at equal degree. However, this situation is unlikely, as we did not watch of the increase of duration of NMDA component of fEPSPs (Fig. 1 and 2), but revealed reduction of pharmacological activity of blockers both non selective and selective for NMDARs comprising NR2A subunit (Tab. 3).

Second, the increase of amplitude of NMDA components of fEPSPs may be an effect of reinforcement of insertion of NMDARs at postsynaptic densities of dendritic spines owing to disfunction of signal pathway adenylate cyclase - cAMP - protein kinase A under conditions of behavioral depression (Yuen et al., 2005 and Liu et al., 2006). Decrease activity of this signal pathway lead to increase at postsynaptic densities of number of NMDARs comprising NR2B subunit. In this case should be observing decrease of pharmacological activity of NMDARs blockers so non selective as selective in respect of NMDARs comprising NR1/NR2B subunit. We did not observe this (Tab. 3).

Third, the observed effects may be conditioned by changes of a chemosensitivity of NMDARs produced by phosphorilation of receptor subunits. It was estabilished that in structure of NMDARs subunits the residues of serine/threonine or tyrosine are phosphorilating by different protein kinases. It may be phosphorilation of tyrosine at stucture of NMDSRs subunit produced by hormones of stress and by proinflammatory interleukines and also phosphorilation of serine or threonine produced by prostaglandines (Viviani et al., 2003 and Akaneya, 2007). The tyrosine residues are phosphorilated in structure only $1-2 \%$ of NMDARs at intact animals; phosphorilation of tyrosine residues at stucture of NMDSRs NR2A, but not NR2B subunit substantially increase under stress and inflammation conditions (Tezuka et al., 1999). It produces the increase of NMDARs chemosensitivity and must be attended by gain of amplitude of the synaptic potentials evoked by activation of NR1/NR2A NMDARs and attenuation of the pharmacological activity so ketamine as $\mathrm{Zn}^{2+}$. This we observed in our experiments (Fig. 1 and 2, Tab. 3).

It seems at first blush that observed changes of synaptic plasticity of the mPFC 
pyramidal neurons (Fig. 3) are conditioned by increase of functional activity of NMDARs (Fig. 1 and 2). Whereas induction of LTP and LTD in mPFC used in our experiments is NMDA-dependent, it should to anticipate on gain of expression of these forms of synaptic plasticity. It was observed the intensification of the synaptic plasticity at mice with genetic overproduction of NMDARs, while at mice with genetic deletion of the NR2 subunits expression of LTP was inhibited (Sakimura et al., 1995 and Tang et al., 1999). However we observed in our experiments inhibition of expression of LTP and LTD, besides LTD in case of social isolation (Fig. 3). Therefore changes of synaptic plasticity are disconnected with increase of functional activity of the NMDARs. Attenuation of these changes of synaptic plasticity by the calcium antagonist verapamil (Fig. 3) allows to think, that abnormalities in expression of LTP and LTD at mPFC under behavioral depression are conditioned by growth of functional activity of voltagedependent $\mathrm{Ca}^{2+}$ channels (VDCC) L-type. It increases amplitude of the afterhyperpolarization (AHP), which reinforces blockade of the cation channels of NMDARs by $\mathrm{Mg}^{2+}$ and restricts influx of $\mathrm{Ca}^{2+}$ at the dendrite spines during tetanic stimulation of synaptic inputs (Sah, Bekkers, 1996). On the other hand, growth of functional activity of VDCC reinforces a VDCC-dependent component of LTD induction (Cousens et al., 2006) and facilitates it expression under social isolation (Fig. 3). Inhibition of LTD expression under chronic inflammation is conditioned probably by chemoinduced LTD evoked by the proinflammatory interleukines, which blocks expression of tetanus-induced LTD (Ikegaya et al., 2003).

\section{Conclusion}

The changes of the synaptic functions of the pyramidal neurons of mPFC under evoked by social isolation and chronic inflammation behavioral depression proceeded into three directions. It was the decrease of amplitude of fEPSPs, i. e. inhibition of fast glutamatergic synaptic transmission. Further, it was observed the increase of NMDA component of fEPSPs, i. e. gain of functional activity of NMDARs. Finally, it was revealed inhibition of expression of tetanus-induced LTP and LTD, but facilitation of LTD development under social isolation. It considers that disturbances of relay properties of glutamatergic synapses are conditioned by increase of functional activity of NMDARs, while disturbances of their plastic propertirs - by increase of VDCC activity.

\section{Acknowledgments}

We thank Dr Yurii V. Kidin for useful discussion and valuable comments.

\section{References}

Abramets, I. I., Evdokimov, D. V. \& Talalayenko, A. N. (2007). 'Alterations of Plastic Qualities and Metaplasticity of the Glutamatergic Synapses at the Rat Cortex and Hippocampus against the Backgrond Reserpine Behavioral Depression,' Neurophysiologia 39 (2) 214 - 221. (Article on Russian)

Abramets, I. I., Talalayenko, A. N., Evdokimov, D. V. \& Frolkov, V. V. (2005). 'Central Glutamatergic Synaptic Transmission at Circumstances of Behavioral Depression at Rats,' Neurosciences: Teoretical \& Clinical Aspects 1 (1) 22 - 30. (Article on Russian)

Akaneya, Y. (2007). "The Remarkable Mechanism of Prostaglandin E2 on Synaptic Plasticity," Gene Regulation and Systems Biology 1 (1) 83 - 89.

Berman, R. M., Cappiello, A., Anand, A., Oren, D. A., Heninger, G. R., Charney, D. S. et al. (2000). "Antidepressant Effects of Ketamine in Depressed Patients," Biological Psychiatry 47 (4) 351 - 354.

Burnham, W. M., Cottrell, G. A., Diosy, D. \& Racine, R. J. (1995). "Long-term Changes in Enthorhinal-Dentate Evoked Potentials Induced by Electroconvulsive Shock Seizures in Rats," Brain Research 698 (1) $180-184$.

Cappiello, A., Charney, D. S. \& Berman, R. (1997). 'NMDA Receptor Function in Major 
Depression,' Molecular Psychiatry 41 (1) 45S.

Cousens, C. M., Kerr, D. S. \& Abraham, W. C. (1997). "Glucocorticoid Receptor Activation Lowers the Threshold for NMDA Receptor-Dependent Homosynaptic LongTerm Depression in the Hippocampus through Activation of Voltage-Dependent Calcium Channels," Journal of Neurophysiology 78 (1) 1 - 9 .

Derkach, V. A., Oh, M. C., Guire, E. S. \& Soderling, T. R. (2003). 'Regulatory Mechanisms of AMPA Receptors in Synaptic Plasticity,' Nature Review Neuroscience 4 (2) 101 - 113.

Ehlers, M. D., Heine, M., Groc, L., Lee, M. C. \& Choquet D. (2007). "Diffusional Trapping of GluR1 AMPA Receptors by Input-Specific Synaptic Activity," Neuron 54 (3) 447 460.

Fortin, D. A. \& Levine, E. S. (2007). "Differential Effects of Endocannabinoids on Glutamatergic and GABAergic Inputs to Layer 5 Pyramidal Neurons," Cerebral Cortex 17 (1) 163 - 174.

Handley, S. L. \& Mithani, S. (1984). "Effects of Alpha-Adrenoceptor Agonists and Antagonists in a Maze-Exploration of "Fear"-Motivated Behaviour," NaunynSmiedebergs Archives of Pharmacology 327 (1) $1-5$.

Hestrin, S., Nicoll, R. A., Perkel, D. J. \& Sah, P. (1990). "Analysis of Excitatory Synaptic Action in Pyramidal Cells Using Whole-Cell Recording from Rat Hippocampal Slices," Journal of Physiology (Lond) 422 (1) 203 225.

Ikegaya, Y., Delcroix, I., Iwakura, Y., Matsuki, N. \& Nishiyama, N. (2003). "Interleukin-1 Abrogates Long-Term Depression of Hippocampal CA1 Synaptic Transmission," Synapse 47 (1) 54 - 57.

Ilyin, V. I., Wittermore, E. R., Guastella, J., Weber, E. \& Woodward, R. M. (1996). "Subtype Selective Inhibition of N-MethylD-Aspartate Receptors by Haloperidol,"
Molecular Pharmacology 50 (6) 1541 1550.

Izumi, Y., Auberson, Y. P. \& Zorumski, C. F. (2006). "Zinc Modulates Bidirectional Hippocampal Plasticity by Effects on the NMDA Receptors," Journal of Neuroscience 26 (18) 7181 - 7188.

Kato, K., Sekino, Y., Takahashi, H., Yasuda, H. \& Shirao T. (2007). "Increase in AMPA Receptor-Mediated Miniature EPSC Amplitude after Chronic NMDA Receptor Blockade in Cultured Hippocampal Neurons," Neuroscience Letters 418 (1) 4 8.

Knoll, J., Kolemen, K. \& Knoll, B. (1955). 'A Method for the Elaboration of a NonExtinguishable Conditioned Reflex in the Rat,' Acta Physiologica of Academy Science of Hungary 6 (3) 327 - 345.

Kohr, G. (2006). "NMDA Receptor Function: Subunit Composition versus Spatial Distribution," Cell and Tissue Research 326 (3) $439-446$.

Krystal, J. H., Sanacora, G., Blumberg, H., Anand, A., Charney, D. S., Marek, G. et al. (2002). "Glutamate and GABA Systems as Target for Novel Antidepressant and MoodStabilizing Treatments," Molecular Psychiatry 7 (1) S71 - S80.

Lau, C. G. \& Zukin, R. S. (2007). "NMDA Receptor Trafficking in Synaptic Plasticity and Neuropsychiatric Disorders," Nature Review Neuroscience 8 (4) 413 - 426.

Li, X., Tizzano, J. P., Griffey, K., Clay, M., Lindstrom, T. \& Skolnic, P. (2001). "Antidepressant-Like Activity of AMPA Potentiator (LY392098)," Neuropharmacology 40 (8) 1028 - 1033.

Liu, W., Yuen, E. Y., Allen, P. B., Feng, J., Greengard, P. \& Yan, Z. (2006). "Adrenergic Modulation of NMDA Receptors in Prefrontal Cortex is Differentially Regulates by RGS Proteins and Spinophilin," Proceedings of the National Academy of Sciences USA 103 (48) 18338 - 18343. 
Malandro, M. S. \& Kilberg, M. S. (1996). "Molecular Biology of Mammalian Amino Acid Transporters," Annual Review of Biochemistry 65 (2) 305 - 336.

Mayberg, H. S., Liotti, M., Branna, S. K., McGinnis, S., Mahurin, R. K., Jerabek, P. A et al. (1999). "Reciprocal Limbic-Cortical Function and Negative Mood: Converging PET Findings in Depression and Normal Sadness," American Journal of Psychiatry 156 (3) 675 - 682.

Moore, G. J., Cortese, B. M., Glitz, D. A., ZajacBenitez, C., Quiroz, J. A., Uhde, T. W. et al. (2009). "A Longitudinal Study of the Effects of Lithium Treatment on Prefrontal and Subgenual Prefrontal Gray Matter Volume in Treatment Responsive Bipolar Disorder Patients," Journal of Clinical Psychiatry 70 (3) $699-705$.

Muller, N. \& Schwarz, M. J. (2007). "The Immune Mediated Alteration of Serotonin and Glutamate towards on Integration View," Molecular Psychiatry 12 (5) 988 1000.

Pickering, C., Gustafsson, L., Cebere, A., Nylander, I. \& Liljequist, S. (2006). "Repeated Maternal Separation of Male Wistar Rats Alters Glutamate Receptor Expression in the Hippocampus but not the Prefrontal Cortex," Brain Research 1099 (1) 101-108.

Porsolt, R. D., Bertin, A. \& Jalfre, M. (1978). "Behavioural Despair" in Rats and Mice: Strain Differences and Effects of Imipramine," European Journal of Pharmacology 51 (3) 291 - 294.

Price, J. L. \& Drevets, W. C. (2010). "Neurocircuitry of Mood Disorder," Neuropsychopharmacology 35 (1) 192 216.

Sah, P. \& Bekkers, J. M. (1996). 'Apical Dendritic Location of Slow after hyperpolarization Current in Hippocampal Pyramidal Neurons: Implication for the Integration of Long-Term Potentiation,' Journal of Neuroscience 16 (15) 45374542.
Sakimura, K., Kutsuwada, T., Ito, I., Manabe, T., Takayama, C., Kushiya, E. et al. (1995). "Reduced Hippocampal LTP and Spatial Learning in Mice Lacking NMDA Receptor Epsylon 1 Subunit," Nature 373 (6510) 151 $-155$.

Shi, J., Aamodt, S. M., Townsend, M. \& Constantine-Paton, M. (2001). "Developmental Depression of Glutamate Neurotransmission by Chronic Low-Level Activation of NMDA Receptors," Journal of Neuroscience 21 (16) 6233 - 6244.

Tang, Y. P., Shimizu, E., Dube, G. R., Rampon, C., Kerchner, G. A., Zhuo, M. et al. (1999). "Genetic Enhancement of Learning and Memory in Mice," Nature 401 (6748) 63 69.

Tezuka, T., Umemori, H., Akiyama, T., Nakanishi, S. \& Yamammoto, S. (1999). "PSD-95 Promotes Fyn-Mediated Tyrosine Phosphorilation of the N-Methyl-DAspartate Receptor Subunit NR2A," Proceedings of the National Academy of Sciences USA 96 (1) 435 - 440.

Trinus, F. P., Mohort, N. A. \& Klebanov, B. M. (1975). 'Nonsteroid Antiinflammation Drugs,' Zdorov'ya, Kiev, UA.

Viviani, B., Bartesaghi, S., Gardoni, F., Vezzani, A., Behrens, M. M., Bartfai, T. et al. (2003). 'Interleukin-1 Beta Enhances NMDA Receptor-Mediated [Ca2+]i Increase and Neurotoxicity,' Journal of Neurosience 23 (25) $8692-8700$.

Yang, S., Liu, Z.- W., Wen, L., Qiao, H.- F., Zhou, W.- X. \& Zhang, Y.- X. (2005). "Interleukin-1 $\beta$ Enhances NMDA ReceptorMediated Current but Inhibits Excitatory Synaptic Transmission," Brain Research 1034 (1) $172-179$.

Yuen, E. Y., Jiang, Q., Chen, P., Gu, Z., Feng, J. \& Yan, Z. (2005). "Serotonin 5-HT1A Receptors Regulate NMDA Receptor Channels through a MicrotubuleDependent Mechanim," Journal of Neuroscience 25 (23) 5488 - 5501. 
Zushida, K., Sakurai, M., Wada, K. \& Sekiguchi, M. (2007). "Facilitation of Extinction Learning for Contextual Fear Menory by PEPA: A Potentiator of AMPA Receptors," Journal of Neuroscience 27 (1) $158-166$. 